\section{Comparative Atherosclerosis}

The Morphology of Spontaneous and Induced Atherosclerotic Lesions in Animals and its Relation to Human Disease. Edited by James C. Roberts and Reuben Straus, with Miriam S. Cooper. Pp. xxi $+426+$ Atlas of Colour Plates. (New York and London: Hoeber Medical Division, Harper and Row, 1965.) 150s.

7 HIS volume arose primarily under the impetus of a conference on comparative atherosclerosis, and its fifty-six authors are leading investigators in this field.

The primary purpose of the volume was "to ferret out and consolidate valuable knowledge buried amid the welter of accumulated information in the literature. A need was recognized for an authoritative reference which would compile and catalogue this knowledge in logical sequence and accessible form, sharply delineate differences and similarities of the disease in all species of animals, and determine which animals are acceptable as models for the most vital phase of all this research effort, which is the testing of mechanisms and materials to understand, prevent, and/or treat atherosclerotic disease in man".

Observations on more than four hundred species of animals are discussed and co-ordinated in seven principal sections dealing, respectively, with atherosclerosis in swine, birds, rats and wild animals, canines, primates, rabbits and man. The eighth section is devoted to summaries of more general problems such as: $(a)$ the histochemistry of spontaneous and experimental arterial lesions; (b) the relationship between spontaneous atherosclerosis in animals and man; (c) comparison of experimentally induced atherosclerosis in animals with spontaneous human atherosclerosis; $(d)$ an outlook which probes the probable future of research in this field.

The professional investigator will undoubtedly profit by the exceptionally clear and well-organized presentation of this immense material. It will permit him to select those animal species which suit his immediate purpose best and help him to find his way across the enormous literature which deals with this important field.

Not the least attractive feature of this 426-page volume are the 672 illustrations, including an atlas of 416 excellent coloured photographs and a meticulously prepared index.

H. SeLYe

\section{Canine and Feline Nutritional Requirements}

Edited by Oliver Graham-Jones. (Proceedings of a Symposium organized by the British Small Animals Veterinary Association, London, May 1964.) Pp. $x+160$ (London and New York: Pergamon Press, Ltd., 1965.) 63s. net.

7 HIS volume contains the proceedings of a symposium organized in 1964 by the British Small Animals Veterinary Association, with the object of bringing together information gained by scientific workers in the field of nutrition, and the practical experience of veterinary surgeons.

The book is divided into two sections; the first is mainly theoretical, and contains a review of the growth, development, and chemical maturation of pups and kittens during the suckling period, and leads naturally to a discussion of protein and calorie requirements, and of the problems involved in the design and evaluation of diets. Some special aspects of the nutrition of the cat are dealt with in separate chapters. Two chapters in this section emphasize the importance of the interrelationships between nutrients and between the diet and other factors, as exemplified by investigations of the effects of different diets on the course of Toxocara canis infestation in dogs. The section closes with a description of some diets designed for special purposes such as the treatment of obesity and diabetes in dogs.

The second section, on practical dietetics, contains a review of the requirements of Antarctic sledge dogs, including recommendations for the calorie intakes needed for weight maintenance at different work loads. Following chapters contain information about the breeding and rearing, for laboratory purposes, of dogs and cats on standardized diets and tinned foods, and the conclud. ing chapter describes diets in use at Basle Zoo for all canine and feline animals.

P. R. Payne

\section{Coincidence Tables for Atomic Spectroscopy}

By J. Kuba, L. Kučera, F. Plzák, M. Dvořák and J. Mráz. Pp. xxxi 1,136. (Amsterdam, London and New York: Elsevier Publishing Company, 1965.) $130 s$.

7 HIS large work gives essentially a series of tables showing, for the strongest lines of each element, the likely lines from other elements which might coincide in wave-length over intervals corresponding to three ranges for instruments with dispersions $0.5-20 \AA / \mathrm{mm}$. The authors have been most painstaking and one admires their enthusiasm; one wonders, however, whether such a task could not have been handled both in selection and reproduction by computer techniques. The wave-lengths are based on the lists of G. R. Harrison dating from before 1939, and the opportunity has not been taken of making corrections and improvements from more recent investigations. Thus, work during the past few years on rare earth lines (R. N. Niseley, V. A. Fassel and C. F. Lentz, Spectrochem. Acta, 16, 863; 1960) and spectral-line intensities (W. F. Meggers, C. H. Corliss and B. F. Scribner, U.S. National Bureau of Standards Monograph 32, 1961) has not been included. In some ways recent advances in spectroscopic technique, particularly the increasing use of gratings to give higher dispersions, have helped to decrease errors in analysis arising from the influence of overlapping lines.

British spectroscopists will be grateful that, although the authors are distinguished Czechoslovakian spectrochemists, the book is in English with only minor difficulties of translation, for example, 'self-inversions', and 'ionisation tension'. As a general guide to spectrochemical procedure in wave-length measurement and a convenient summary for identifying lines, the book will form a useful although expensive addition to an analytical laboratory library.

L. BOVEY

\section{Collected Papers of L. D. Landau}

Edited and with an Introduction by D. Ter Haar. Pp. $\mathrm{xx}+836$. (New York: Gordon and Breach; London: Pergamon Press, Ltd., 1965.) 200s.

DERHAPS the most valuable feature of this collection of papers is concerned with the nationality of the author. The most important (in fact, the majority) of Landau's published works are presented in this rather large book, all in English and in chronological order. A few outdated or incorrect works are listed, with comments, in an appendix. The introduction consists of a very short biography and a brief indication of the contents of the papers. My only criticism of the introduction is its brevity and not its existence, the need of which the editor seems to doubt. There are few physicists to-day who are not specialists, which surely implies that the majority of us need some guidance through the works of a man of Landau's range of interests. Those who agree with the editor's sentiment can, of course, skip the introduction.

The publishers are quite right in stating that this book is an "essential addition to the shelves of every library", but it is unlikely that many individual workers will wish to acquire it, due to its high price. There is, however, some hope for the impecunious, since the same publishers are introducing a new series of books entitled Men of Physics, two volumes being devoted to Landau. The combined volumes will contain twenty of the more important papers and will cost 178. 6d. each (paperback). L. L. J. VICK 